\title{
Quantificação de Danos Pós-Colheita em Pêssegos no Mercado Atacadista de São Paulo
}

\author{
Marise C. Martins', Silvia A. Lourenço², Anita S. D. Gutierrez ${ }^{3}$, Angelo P. Jacomino² \& Lilian Amorim² \\ ${ }^{1}$ Instituto Biológico, Setor de Fitopatologia, Cx. Postal 70, CEP 13001-970, Campinas, SP, e-mail: \\ marise@biologico.sp.gov.br; ${ }^{2}$ Escola Superior de Agricultura Luiz de Queiroz, Universidade de São Paulo, Cx. Postal 9, \\ CEP 13418-900, Piracicaba, SP; ${ }^{3}$ Centro de Qualidade em Horticultura, Companhia de Entrepostos e Armazéns Gerais de \\ São Paulo (CEAGESP), Av. Dr. Gastão Vidigal, 1946, CEP 05316-900, São Paulo, SP, e-mail: cqh@ceagesp.com.br
}

(Aceito para publicação em 24/08/2005)

Autor para correspondência: Marise Cagnin Martins

MARTINS, M.C., LOURENÇO, S.A., GUTIERREZ, A.S.D., JACOMINO, A.P. \& AMORIM, L. Quantificação de danos pós-colheita em pêssegos no mercado atacadista de São Paulo. Fitopatologia Brasileira 31:005-010. 2006.

\section{RESUMO}

A ocorrência de distúrbios pós-colheita em pêssegos (Prunus persicae) é considerada uma importante causa de desvalorização do produto por ocasião da comercialização. Este trabalho teve por objetivo quantificar e caracterizar os danos pós-colheita em pêssegos na CEAGESP, o maior entreposto atacadista do Estado de São Paulo. Foram realizados levantamentos da incidência de danos em $1 \%$ dos frutos comercializados na CEAGESP, em cada data de avaliação, nos períodos de outubro de 2001 a janeiro de 2002 e de outubro de 2002 a janeiro de 2003. A amostragem foi estratificada por variedade de pêssego. Todos os frutos da amostra foram avaliados na própria CEAGESP, onde foram quantificados os danos bióticos e abióticos. Frutos com início de podridões, sem a ocorrência de sinais dos patógenos, foram incubados por $48 \mathrm{~h}$ em câmara úmida, período após o qual procedeu-se à identificação do agente causal. Foram amostrados em média 1.835 frutos por avaliação. Os danos pós-colheita variaram de 4,9 a 44,5\% dos frutos amostrados. Danos provocados por fungos variaram de 2,4 a 15,2\%. Foram constatados fungos dos gêneros Rhizopus, Monilinia, Geotrichum, Cladosporium, Fusarium e Alternaria, além de bactérias e de fungos leveduriformes. Esses últimos foram constatados em todas as datas de amostragem em uma representativa fração (até 46\%) dos frutos que apresentavam podridões associadas a ferimentos. Não foi constatada diferença na suscetibilidade das variedades mais comercializadas. Não houve diferença no nível de danos nos frutos comercializados em diferentes embalagens. O nível de dano esteve relacionado unicamente à procedência do fruto.

Palavras-chave adicionais: doenças pós-colheita, Monilia, Rhizopus, Prunus persicae.

\begin{abstract}
Quantification of post harvest damage in peaches in São Paulo's wholesale market

The occurrence of post harvest disturbances in peaches (Prunus persicae) is an important cause of product depreciation during its commercialization. The objectives of this paper were to quantify and characterize the post harvest damage in peaches at CEAGESP, the biggest wholesale market in the State of São Paulo. The incidence of damages was assessed at $1 \%$ of commercialized fruits in CEAGESP, at each evaluation date during the periods of October 2001 to January 2002 and October 2002 to January 2003. The sampling was stratified on the basis of peach variety. All fruits of the sample were evaluated at CEAGESP for quantification of biotic and abiotic damages. Fruits showing initial rotting without any pathogen signs were incubated for $48 \mathrm{~h}$ in a moist chamber and then causal agents were identified. On average, 1835 fruits were sampled in each evaluation. The post harvest damage ranges from 4.9 to $44.5 \%$ of the sampled fruits. Damage due to diseases varied from 2.4 to 15.2\%. Fungi from the genera Rhizopus, Monilinia, Geotrichum, Cladosporium, Fusarium and Alternaria were detected besides bacteria and yeast-like fungi. Yeasts were found at all sampling dates in significant amounts (up to $46 \%$ ) in the fruits which showed rot associated with wounds. There was no difference in susceptibility among the most commercialized varieties. There was also no difference in damage among fruits kept in different types of containers. The level of damage was related only to the provenance of the fruit.
\end{abstract}

Additional keywords: post harvest diseases, Monilia, Rhizopus, Prunus persicae.

\section{INTRODUÇÃO}

Os danos (redução na qualidade ou quantidade de um produto) pós-colheita em pêssegos [Prunus persicae (L.)
Bastch] podem ser de natureza física, fisiológica e patológica e se expressam desde a colheita até seu uso pelo consumidor (Snowdon, 1990; Kluge et al., 2001). Há pouquíssimas avaliações precisas dos danos provocados por anomalias pós- 
colheita em pêssegos nas diferentes fases da cadeia produtiva, sendo todas oriundas de levantamentos realizados nos mercados de Nova Iorque e de Chicago, nos Estados Unidos da América (Cappellini \& Ceponis, 1984; Ceponis et al., 1987). Naqueles mercados, os danos pós-colheita variaram de 2,3 a $12,3 \%$ no mercado atacadista e de 4,5 a $5,8 \%$ no mercado varejista (Cappellini \& Ceponis, 1984). Apesar de aparentemente baixa, a percentagem de perdas no mercado varejista corresponde a 1.810 ton de pêssegos perdidos anualmente, o que é significativo, considerandose o nível tecnológico dos produtores e comerciantes norteamericanos. Apesar de variar de ano para ano, os danos e, conseqüentemente, as perdas pós-colheita são mais elevados em países em desenvolvimento dos trópicos, onde os sistemas de transporte e de refrigeração são, em geral, deficientes (Eckert \& Ogawa, 1988). No Brasil não há nenhuma estimativa confiável dos danos provocados por anomalias pós-colheita em pêssegos, embora a qualidade do fruto produzido no Estado de São Paulo esteja aquém da qualidade dos frutos importados de países do cone sul (Maia et al., 1996). A produção de pêssegos no Estado de São Paulo, segundo maior produtor do País, superado apenas pelo Rio Grande do Sul (Sato, 2001), encontra-se em franca expansão, com aumento de produção de $27,3 \%$ entre 2001 e 2002 (Tsunechiro et al., 2003). Os frutos produzidos no Estado de São Paulo destinam-se primordialmente ao consumo in natura, o que acarreta elevado custo de produção com embalagens (44,8\%) e com defensivos (17,2\%) (Maia et al., 1996). Justifica-se, portanto, a estimativa de danos póscolheita, com ênfase às doenças, para avaliar a eficiência da produção paulista.

A quantificação de danos pós-colheita tem duas funções estratégicas (Baritelle \& Gardner, 1984): a primeira é a de facilitar a tomada de decisão por parte do produtor, do atacadista e do varejista quanto à necessidade de investimento em medidas de prevenção, pois só é possível decidir se a adoção de uma medida de controle será lucrativa ou não após quantificar os danos causados por determinada anomalia; a segunda é a de permitir que políticas públicas sejam adotadas de acordo com critérios explícitos, como por exemplo, o financiamento de projetos de pesquisa na área de pós-colheita em detrimento de outras áreas. Sobre essa segunda função estratégica, Baritelle \& Gardner (1984) questionam a preocupação exagerada da comunidade científica em aumentar a produtividade das culturas quando uma significativa proporção do alimento produzido é perdida após a colheita pelo ataque de fungos, pragas e roedores.

A Companhia de Entrepostos e Armazéns Gerais de São Paulo (CEAGESP) localizada na capital paulista comercializa $12 \%$ da produção brasileira de frutas e hortaliças, provenientes de 1.300 municípios brasileiros. Por essa razão ela constitui-se num excelente ponto de amostragem para levantamentos de distúrbios pós-colheita. Anualmente, a comercialização de pêssegos é feita de setembro a fevereiro, com predominância do produto do Estado de São Paulo entre setembro e dezembro e daquele proveniente da Região Sul do País de dezembro a fevereiro. Os objetivos deste trabalho foram identificar as anomalias e quantificar os danos pós-colheita em pêssegos durante a comercialização atacadista na CEAGESP paulistana, relacionando os danos às variedades, ao tipo de embalagem e à procedência do fruto.

\section{MATERIAL E MÉTODOS}

Foram realizados levantamentos mensais na safra 2001-2002 e semanais na safra 2002-2003 (Tabela 1). Em cada levantamento foram vistoriados todos os pêssegos de $1 \%$ das caixas comercializadas pelos cinco maiores permissionários de pêssego da CEAGESP, totalizando 14.000 frutos na primeira e 25.975 frutos na segunda safra. A seleção das amostras foi feita por amostragem estratificada, utilizando como critério de estratificação a variedade da fruta (Tabela 2). Cada amostra correspondeu a uma caixa de pêssegos. Na safra 2001-2002 todos os tipos de embalagens foram amostrados, enquanto que na safra 2002-2003 apenas as embalagens adequadamente etiquetadas foram vistoriadas. Isso excluiu as embalagens com poucos frutos, normalmente de alta qualidade e embalados individualmente em papel de seda ou similar, pois as mesmas raramente traziam identificação do produtor, do calibre e/ou da variedade de pêssego. Todos os frutos de cada amostra foram inspecionados visualmente e cada anomalia foi descrita num formulário que continha as seguintes informações: número da amostra, data de colheita, procedência (produtor), variedade, calibre, tipo de embalagem (caixas de madeira, de papelão ou de plástico), tipo de acondicionamento dos frutos na embalagem (granel ou em bandejas plásticas), número de frutos por embalagem, anomalias bióticas, anomalias fisiológicas e injúrias mecânicas. Frutos com anomalias bióticas não identificadas foram numerados e acondicionados em embalagens plásticas com células individuais e, em seguida, transportados aos laboratórios da ESALQ, onde foram incubados em câmaras úmidas por $24 \mathrm{~h}$. Após esse período, a câmara foi retirada e os frutos foram submetidos a uma nova inspeção visual, além de análise em microscópio óptico, quando necessária para identificação dos patógenos. Os frutos que permaneciam após esse período com sintomas atípicos e sem a presença de sinais de patógenos foram submetidos a um novo período de $24 \mathrm{~h}$ de câmara úmida, para avaliação posterior. As anomalias de origem abiótica foram separadas em injúria mecânica e anomalia fisiológica, em função da sintomatologia. Foram contabilizados dentro da categoria de injúria mecânica frutos batidos, prensados, raspados, cortados e danificados por chuva de granizo ou pela unha do colhedor.

Os dados da safra 2002-2003 foram submetidos à análise de correlação para relacionar danos mecânicos a danos bióticos e fisiológicos. Esses dados também foram analisados para identificar diferenças de incidência de danos entre os diferentes produtores e de incidência de doenças entre as variedades comercializadas em maior volume 
(Aurora, Chiripá, Dourado, Douradão, IAC e Ouromel). Avaliou-se ainda a influência do tipo de embalagem e do tipo de acondicionamento dos frutos na incidência de danos (mecânicos + bióticos). As comparações da incidência de danos por produtor e da incidência de doenças por variedade foram feitas pelo teste $\mathrm{F}$, considerando cada data de amostragem como uma repetição. Os efeitos do tipo de embalagem e do tipo de acondicionamento dos frutos na incidência de danos foram testados por contrastes ortogonais, considerando-se, também nesse caso, cada data de avaliação como uma repetição.

\section{RESULTADOS}

Os danos pós-colheita, expressos em percentagem de frutos sintomáticos, variaram de 5,9 a $10,6 \%$ na safra 2001 2002 (Figura 1) e de 4,9 a 44,5\% na safra 2002-2003 (Figura 2). A percentagem de frutos doentes variou de 2,4 a 8 (Figura 1) e de 4,3 a 15,2 (Figura 2), respectivamente, nas safras 2001-2002 e 2002-2003. Nas diferentes avaliações, apenas a fenda sutural e a deformação de frutos foram constatadas como anomalias fisiológicas, em baixa freqüência nas duas safras (Figuras 1 e 2). Os danos mecânicos foram, em média, mais elevados que os danos bióticos na safra 2002-2003. Foi constatada correlação entre a freqüência de frutos com dano mecânico e a freqüência de frutos doentes nas diferentes amostras $(\mathrm{r}=0,52)$, o que, de certa forma é esperado, uma vez que a maioria dos patógenos pós-colheita penetra o fruto através de ferimentos. Não houve correlação entre danos mecânicos e danos fisiológicos. A freqüência de amostras

TABELA 1 - Datas de amostragem, número de caixas vistoriadas e número de frutos de pêssego (Prunus persicae) examinados em cada avaliação nas safras 2001-2002 e 2002-2003 na CEAGESP da cidade de São Paulo

\begin{tabular}{lcc}
\hline \hline Data de avaliação & Caixas $\left(\mathbf{n}^{\mathbf{0}}\right)$ & Frutos $\left(\mathbf{n}^{\mathbf{0}}\right)$ \\
\hline Safra 2001 -2002 & & \\
$30 / 10 / 01$ & 16 & 1606 \\
$12 / 11 / 01$ & 40 & 3304 \\
$3 / 12 / 01$ & 52 & 3418 \\
$7 / 01 / 02$ & 49 & 2685 \\
$21 / 1 / 02$ & 44 & 2987 \\
Safra 2002 -2003 & & \\
$9 / 10 / 02$ & 20 & 2549 \\
$16 / 10 / 02$ & 35 & 4008 \\
$22 / 10 / 02$ & 23 & 2281 \\
$29 / 10 / 02$ & 36 & 3453 \\
$5 / 11 / 02$ & 18 & 2047 \\
$12 / 11 / 02$ & 17 & 1724 \\
$20 / 11 / 02$ & 26 & 2542 \\
$26 / 11 / 02$ & 19 & 1687 \\
$2 / 12 / 02$ & 11 & 861 \\
$16 / 12 / 02$ & 16 & 866 \\
$7 / 01 / 03$ & 13 & 934 \\
$14 / 1 / 03$ & 14 & 1239 \\
$21 / 1 / 03$ & 17 & 1225 \\
$28 / 1 / 03$ & 6 & 559 \\
\hline
\end{tabular}

com pelo menos um fruto danificado foi bastante elevada nas duas safras (Tabela 3). Na safra 2002-2003, a partir da terceira data de avaliação, todas as caixas exibiam pelo menos um fruto com alguma anomalia.

Além dos fungos freqüentemente relatados como causadores de doenças pós-colheita de pêssego, como Rhizopus stolonifer (Erhenb.: Fr.) Vuill e Monilinia fructicola (G. Wint.) Honey., foram constatados também os dos gêneros Geotrichum, Cladosporium, Fusarium e Alternaria, além de uma levedura não identificada. Os gêneros fúngicos de ocorrência mais freqüente foram Monilinia, Rhizopus e Cladosporium, além da levedura, já citada, que foi constatada em todas as avaliações das duas safras (Figura 3). A presença dessa levedura esteve sempre associada a ferimentos nos frutos.

As variedades Aurora, Chiripá, Dourado, Douradão, IAC e Ouromel não apresentaram diferenças significativas $(p=0,196)$ na incidência de doenças. Não foi constatado efeito do tipo de embalagem (plástico, madeira ou papelão, $p=0,854)$ nem do tipo de acondicionamento dos frutos (bandejas plásticas ou granel, $p=0,681$ ) na incidência de danos mecânicos e bióticos. A única fonte de variação que explicou a diferença de incidência dos danos entre as amostras foi o produtor $(p=0,015)$.

\section{DISCUSSÃO}

Pêssegos são frutos delicados, bastante sensíveis a injúrias pós-colheita. Dentre as rosáceas de caroço, a suscetibilidade a distúrbios pós-colheita só é maior nas cerejas e nectarinas (Cappellini \& Ceponis, 1984; Salunke

TABELA 2 - Representatividade (percentagem) de cada variedade de pêssego (Prunus persicae) no total de amostras analisadas nas safras 2001-2002 e 2002-2003 na CEAGESP da cidade de São Paulo

\begin{tabular}{lcc}
\hline \hline Variedade & Safra 2001 -2002 & Safra 2002 -2003 \\
\hline Chiripá & 39,9 & 15,9 \\
Aurora & 12,1 & 25,7 \\
Dourado & 9,9 & 21,9 \\
Douradão & 6,2 & 7,3 \\
Coral & 6,1 & - \\
Premier & 4,0 & 1,1 \\
Chimarrita & 3,9 & 2,7 \\
Ouromel & 3,9 & 5,7 \\
Marli & 3,8 & 2,1 \\
Beauty & 3,2 & 2,7 \\
Natal & 2,0 & - \\
Tropical & 1,8 & - \\
Flor da Prince & 1,5 & 1,5 \\
Diamante & 0,8 & - \\
Eldorado & 0,6 & - \\
Regis & 0,3 & 1,1 \\
IAC & - & 7,9 \\
Flor 4/11/12 & - & 3,1 \\
Dourado 2/3 & - & 0,8 \\
Jóia 4 & - & 0,5 \\
\hline
\end{tabular}




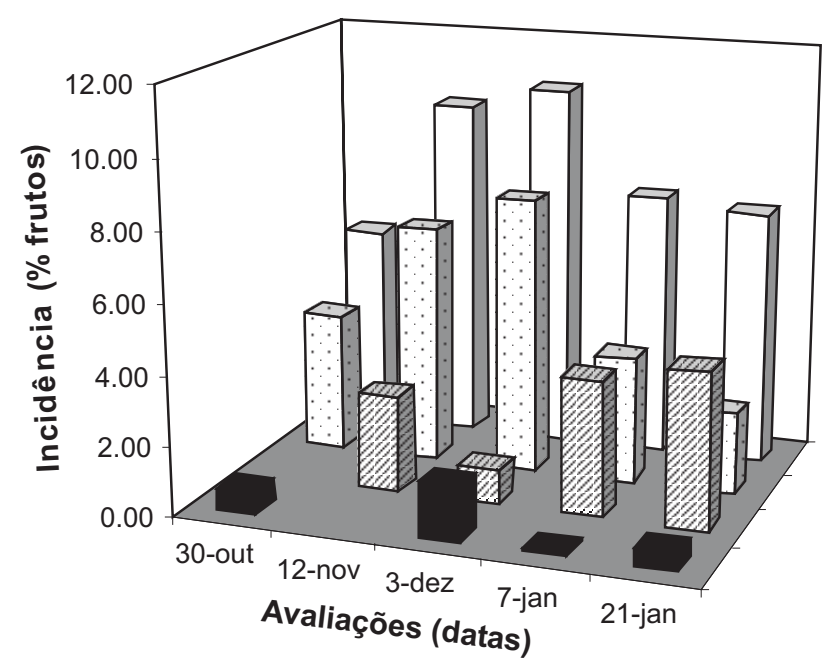

FIG. 1 - Percentagem de danos pós-colheita em pêssegos (Prunus persicae) na safra 2001-2002 avaliados na CEAGESP da cidade de São Paulo. Barras negras representam as anomalias fisiológicas, barras pontilhadas, as doenças, barras hachuradas, as injúrias mecânicas e barras brancas, o total dos danos.

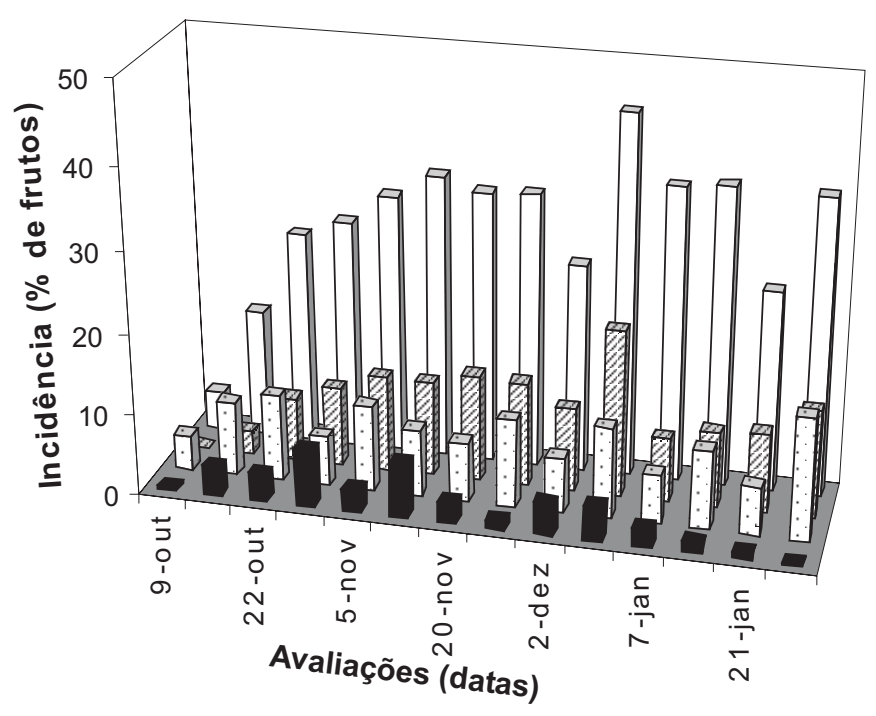

FIG. 2 - Percentagem de danos pós-colheita em pêssegos (Prunus persicae) na safra 2002-2003 avaliados na CEAGESP da cidade de São Paulo. Barras negras representam as anomalias fisiológicas, barras pontilhadas, as doenças, barras hachuradas, as injúrias mecânicas e barras brancas, o total dos danos.

\& Desai, 1984; Eckert \& Ogawa, 1988). Essa suscetibilidade a distúrbios pós-colheita, especialmente às podridões fúngicas, é o principal fator limitante para o armazenamento de pêssegos in natura (Karabulut \& Baykal, 2002). Os níveis de danos constatados na safra 2002-2003 na CEAGESP paulistana foram superiores aos relatados nos Estados Unidos da América (Cappellini \& Ceponis, 1984), principalmente aqueles devido a doenças fúngicas. Em São Paulo, a média de frutos doentes nas duas safras foi de $6,2 \%$, enquanto que nos Estados Unidos esse valor foi de 2,4\% no mercado de Chicago e de $0,7 \%$ no de Nova Iorque (Cappellini \& Ceponis, 1984). A comparação dos dados brasileiros com os americanos, entretanto, deve ser cuidadosa, pois aqui, na impossibilidade de um diagnóstico preciso durante a avaliação no mercado atacadista, os frutos foram expostos a câmaras úmidas por até $48 \mathrm{~h}$ a fim de induzir a formação de sinais dos patógenos, enquanto que no relato americano, os danos referem-se unicamente à inspeção visual nas caixas de comercialização durante o desembarque no mercado atacadista. Em função da diferença na metodologia de determinação de danos, é esperada uma maior percentagem de frutos doentes no caso paulistano. Quando se compara a freqüência de caixas com a presença de pelo menos uma anomalia, dados brasileiros e americanos tornam-se ainda mais próximos. Abrasão e prensagem de frutos foram constatadas em 2.268 carregamentos de pêssegos de um total de 2.610, inspecionados entre 1972 e 1985 no mercado atacadista de Nova Iorque, o que representa $86,9 \%$ do total (Ceponis et al., 1987). Outros danos mecânicos foram relatados em mais de 1.500 carregamentos. Infelizmente, os resultados de Ceponis et al. (1987) não são prontamente comparáveis aos brasileiros, pois o tratamento dos dados foi diferente. Naquele artigo não está apresentada a percentagem total de danos por carregamento nem a percentagem de carregamentos com pelo menos um tipo de dano. Os dados referem-se à percentagem de carregamentos com determinado dano, individualmente. Assim, em 86,9\% dos carregamentos amostrados houve abrasão, em $25 \%$, podridão de Rhizopus, em 2,5\%, podridão parda e assim por diante, mas é impossível saber se houve algum carregamento sem dano. De qualquer forma, a freqüência mínima de carregamentos com pelo menos um fruto danificado foi de $86,9 \%$, mas muito provavelmente o valor total tenha sido superior. A freqüência de caixas com pelo menos um fruto danificado foi também muito elevada em São Paulo na safra 2002-2003, com $100 \%$ das amostras mostrando pelo menos um fruto danificado a partir da terceira avaliação (Tabela 3). Os menores valores observados na safra 2001-2002 devem-se provavelmente ao fato de, naquela safra, terem sido avaliadas embalagens destinadas ao mercado varejista, com poucos frutos, individualmente envoltos em papel de seda ou similar. Nessas embalagens praticamente não havia frutos danificados.

Os dados alarmantes da ocorrência de até $50 \%$ de danos pós-colheita em países em desenvolvimento, muito mais elevados que aqueles constatados em países desenvolvidos (Eckert \& Ogawa, 1988), não foram observados nos levantamentos realizados com a cultura do pêssego, apesar da elevada perecibilidade desses frutos. Isso não quer dizer que os valores brasileiros sejam baixos, pois neste trabalho os danos foram avaliados em um único ponto da cadeia produtiva. Uma visão holística dos danos deveria 
TABELA 3 - Proporção de amostras [caixas de pêssegos (Prunus persicae)] com danos bióticos e mecânicos nas safras 2001-2002 e 2003-2003

\begin{tabular}{lcc}
\hline \hline Data de avaliação & $\begin{array}{c}\text { Danos Bióticos } \\
\text { (proporção) }\end{array}$ & $\begin{array}{c}\text { Danos mecânicos } \\
\text { (proporção) }\end{array}$ \\
\hline Safra 2001 -2002 & 0,63 & - \\
$30 / 10 / 01$ & 0,53 & 0,68 \\
$12 / 11 / 01$ & 0,60 & 0,38 \\
$3 / 12 / 01$ & 0,61 & 0,71 \\
$7 / 01 / 02$ & 0,55 & 0,84 \\
$21 / 1 / 02$ & & \\
Safra 2002 -2003 & 0,85 & 0,15 \\
$9 / 10 / 02$ & 0,91 & 0,74 \\
$16 / 10 / 02$ & 0,83 & 1,00 \\
$22 / 10 / 02$ & 0,86 & 1,00 \\
$29 / 10 / 02$ & 0,83 & 1,00 \\
$5 / 11 / 02$ & 0,71 & 1,00 \\
$12 / 11 / 02$ & 0,73 & 1,00 \\
$20 / 11 / 02$ & 0,47 & 1,00 \\
$26 / 11 / 02$ & 0,64 & 1,00 \\
$2 / 12 / 02$ & 0,69 & 1,00 \\
$16 / 12 / 02$ & 0,77 & 1,00 \\
$7 / 01 / 03$ & 0,93 & 1,00 \\
$14 / 1 / 03$ & 0,82 & 1,00 \\
$21 / 1 / 03$ & 0,67 & 1,00 \\
$28 / 1 / 03$ & &
\end{tabular}

levar em conta todas as fases da cadeia, desde a colheita até a mesa do consumidor.

A semelhança nos níveis de danos constatados nas embalagens de diferentes materiais - caixas de madeira, papelão e plástico - não deixa de ser surpreendente, pois as caixas de madeira e de plástico, por serem mais rígidas que as de papelão, deveriam favorecer o aparecimento de injúrias físicas. A não detecção de diferenças estatísticas significativas entre embalagens de diferentes materiais deveu-se à elevada variabilidade na quantidade de frutos danificados por caixa, mais relacionada à procedência do produto, do que propriamente ao material de embalagem. $\mathrm{O}$ mesmo fato foi constatado nas bandejas plásticas que mostraram similaridade de danos aos de frutos comercializados a granel. Nesse caso específico, constatouse um fato agravante relacionado à retenção de umidade nas bandejas plásticas, que por não serem perfuradas, acabam favorecendo a expressão de doenças. Normalmente, o pêssego embalado em bandejas plásticas é refrigerado na produção e no transporte e a cadeia de frio é quebrada no varejo e no atacado, provocando aumento de umidade nos frutos. Nas embalagens onde as bandejas plásticas foram usadas, a incidência média de doenças foi de $6,5 \%$, enquanto que naquelas onde os frutos estavam soltos (granel) a incidência média foi de 5,6\%. A vantagem da bandeja plástica, que evita o atrito entre os frutos, minimizando danos abióticos, foi perdida pelo acúmulo de umidade, favorável ao desenvolvimento de patógenos.

Um fruto de boa qualidade deve ter recebido tratamento adequado desde sua formação no campo, de tal modo que a qualidade do fruto seja inerente aos tratos culturais pré-colheita. As boas práticas pós-colheita servem apenas para assegurar a manutenção dessa qualidade. Um fruto colhido com defeitos não pode ser sanado na póscolheita. Dessa forma, os dados deste trabalho são bastante ilustrativos, pois mostraram que é o produtor de pêssego quem dita a qualidade de seu produto. A escolha de embalagens não se sobrepõe ao manejo do campo, mas serve para minimizar a ocorrência de problemas adicionais após a colheita.

A ocorrência sazonal de podridão parda na safra 2002-2003 (Figura 3B) indica que essa doença deve ser melhor controlada pelos produtores de pêssego da Região Sul, já que o aumento da doença coincidiu com o aumento da oferta do produto dessa região no mercado. Já a ocorrência de podridões de Cladosporium e de leveduras, ambas associadas a ferimentos no fruto, deve ser o foco do controle no Estado de São Paulo.
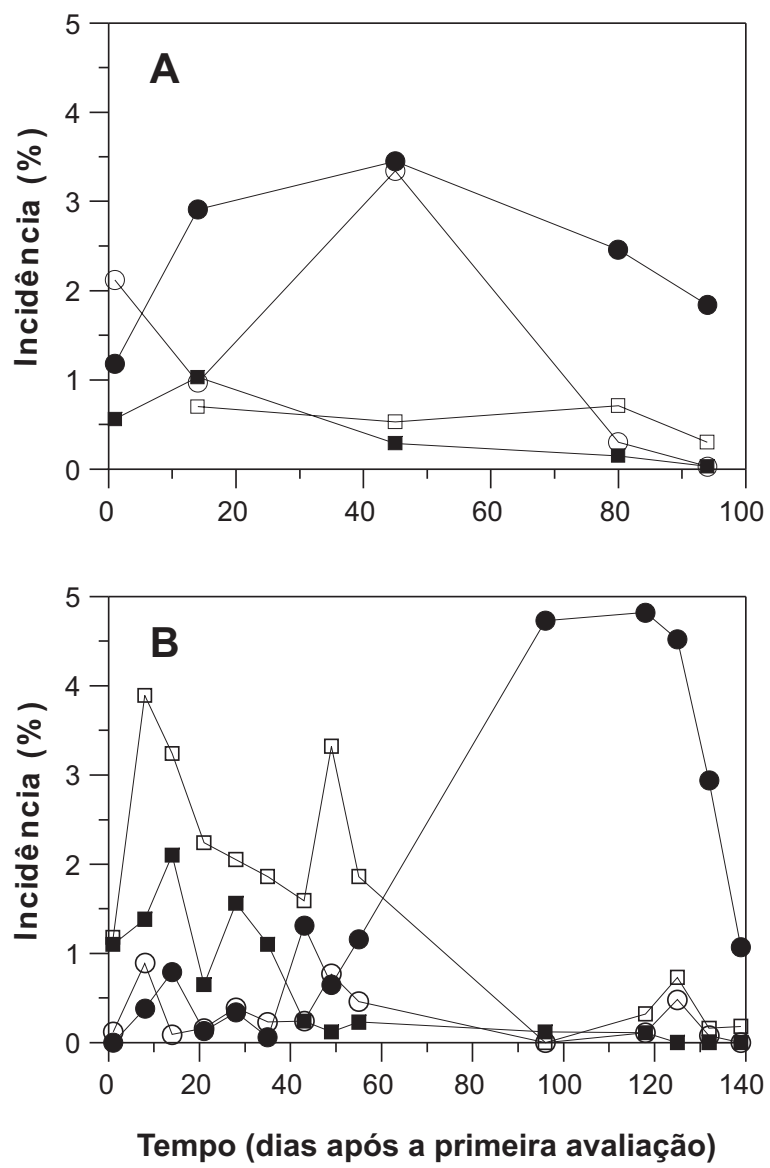

FIG. 3 - Patógenos constatados em amostras de pêssegos (Prunus persicae) nas diferentes datas de avaliação nas safras 2001-2002 (A) e 2002-2003 (B) na CEAGESP da cidade de São Paulo. Cículos cheios representam incidência de podridão parda, círculos vazios, podridão de Rhizopus, quadrados cheios, podridão de Cladosporium e quadrados vazios, podridão de leveduras. 


\section{REFERÊNCIAS BIBLIOGRÁFICAS}

BARITELLE, J.L. \& GARDNER, P.D. Economic losses in the food and fiber system: from the perspective of an economist. In: Moline, H.E. (Ed.) Postharvest Pathology of Fruits and Vegetables: Postharvest Losses in Perishable Crops. University of California Agricultural Experiment Station Bulletin 1914. 1984. pp.4-10.

CAPPELLINI, R.A. \& CEPONIS, M.J. Postharvest losses in fresh fruits and vegetables. In: Moline, H.E. (Ed.) Postharvest Pathology of Fruits and Vegetables: Postharvest Losses in Perishable Crops. University of California Agricultural Experiment Station Bulletin 1914. 1984. pp.24-30.

CEPONIS, M.J., CAPPELlini, R.A., WELls, J.M. \& LIGHTNER, G.W. Disorders in plum, peach, and nectarine shipments in the New York market, 1972-1985. Plant Disease 71:947-952. 1987.

ECKERT, J.W. \& OGAWA, J.M. The chemical control of postharvest diseases: deciduous fruits, berries, vegetables and root/ tuber crops. Annual Review of Phytopathology 26:433-469. 1988.

KARABULUT, O.A. \& BAYKAL, N. Evaluation of the use of microwave power for the control of postharvest diseases of peaches. Postharvest Biology and Technology 26:237-240. 2002.

KLUGE, R., SCARPARE FILHO, J.A., JACOMINO, A.O. \& PEIXOTO, C.P. Distúrbios fisiológicos em frutos. Piracicaba. FEALQ. 2001.

MAIA, M.L., AMARO, A.A., GONÇALVES, J.S. \& SOUZA, S.A. Produção e mercado de pêra e pêssego no Brasil. Informações econômicas 26:33-48. 1996

SATO, G.S. Produção de pêssegos de mesa e para a indústria no Brasil. Informações econômicas 31:61-63. 2001.

SALUNKE, D.K. \& DESAI, B.B. Postharvest Biotechnology of Fruits.v.1. Boca Raton. CRC. 1984.

SNOWDON A.L. A Colour Atlas of Postharvest Diseases and Disorders of Fruit and Vegetables. V.1. General Introduction and Fruits. London. Wolfe Scientific. 1990.

TSUNECHIRO, A., COELHO, P.J., CASER, D.V., AMARAL, A.M.P., MARTINS, V.A. \& BUENO, C.R.F. Valor da produção agropecuária do Estado de São Paulo em 2002. 2003. Disponível em: <http://www.iea.sp.gov.br> acesso em 1 de julho de 2003. 